\title{
PENERAPAN METODE PERAMALAN SEBAGAI ALAT BANTU UNTUK MENENTUKAN PERENCANAAN PRODUKSI PADA PERCETAKAN SURAT KABAR
}

\author{
M. Rizki Ikhsan' ${ }^{1}$, Agustina Tumanggor ${ }^{2}$ \\ ${ }^{1,2}$ Jurusan Teknik Industri, Fakultas Sains dan Teknologi, Universitas Sari Mulia \\ Jl. Pramuka No.2 Pemurus Luar Banjarmasin Kalimantan Selatan \\ Email : agustina.hotma@gmail.com
}

\begin{abstract}
Abstrak-Tujuan penelitian adalah untuk melakukan peramalan permintaan tinta di PT. XYZ karena keadaan permintaan surat kabar setiap harinya berubah sehingga berpengaruh terhadap tinta cetak. Metode penelitian yang digunakan adalah Metode Pemulusan Eksponensial Tunggal (Single Exponential Smoothing), Regresi Linier dan Metode Analisis Data Agregat dengan Jadwal Induk Produksi (Master Production Scheduled). Hasil penelitian ini menurut Metode Pemulusan Eksponensial Tunggal (Single Exponensial Smoothing) diperoleh nilai kesalahan yang lebih kecil, dimana masing-masing itemnya adalah sebagai berikut diperoleh nilai kesalahan yang lebih kecil, dimana untuk masing-masing itemnya adalah sebagai berikut: untuk Tinta Web Cyan menghasilkan untuk periode selanjutnya diramalakan jumlah pemakaiannya sebesar 4,23 Kg. Pada Tinta Web Magenta menghasilkan untuk periode selanjutnya diramalkan jumlah pemakaiannya sebesar 3,73 Kg. Pada Tinta Web Yellow menghasilkan untuk periode selanjutnya diramalkan jumlah pemakaianya sebesar 5,58 Kg. Pada Tinta Web Black menghasilkan untuk periode selanjutnya diramalkan jumlah pemakaiannya sebesar $25.15 \mathrm{Kg}$. maka semakin baik pula peramalan karena semakin kecil tingkat kesalahan pada ramalan.
\end{abstract}

Kata Kunci : Jadwal Induk Produksi, Linier regresi, Pemulusan Eksponential Tunggal.

\section{PENDAhuluan}

PT. XYZ adalah industri yang bergerak dibidang percetakan surat kabar khusus daerah Kalimantan Selatan, Percetakan yang ada saat ini tidak muncul dengan sendirinya, tetapi dimulai oleh beberapa orang sehingga percetakan dapat dikenal saat ini. Percetakan pertama kali ditemukan oleh Masyarakat Cina pada Abad 14 sehingga tak heran jika kebanyakan mesin cetak terbuat dan bermerk berasal dari Cina.

Percetakan yang ada di Benua Eropa ditemukan informasi yang tercatat ditulis dengan tangan. Buku-buku dengan teliti disalin oleh ahli tulis (scribes) yang sering menghabiskan waktu bertahun-tahun untuk menyelesaikan satu jilid buku. Pada PT. XYZ memiliki 1 mesin cetak surat kabar offset Web Goss Community Four Tower. Pada mesin tersebut memiliki 4 macam tinta yang digunakan yaitu: tinta merah (web magenta), tinta biru (web cyan), tinta kuning (web yellow) dan tinta hitam (web black). Warna-warna bisa didapatkan dengan menimpakan beberapa pola warna dari setiap pelat offset sekaligus. Kejelian dalam menentukan warna dan jenis kertas yang digunakan di setiap cetak yang diinginkan, membuat hasil cetakan akan lebih bagus dan maksimal serta profesional. Kapasitas produksi tinta mempengaruhi ketersedian tinta yang diperlukan dalam produksi.

Dengan permasalahan di atas maka penelitian ini mengangkat bagaimana menganalisis pemakaiaan tinta dan kapasitas yang diperlukan pada Mesin Web Goss Community Four Tower di PT. XYZ. Penelitian ini berjudul "Penerapan Metode Peramalan Sebagai Alat Bantu Untuk Menentukan Perencanaan Produksi pada Percetakan Surat Kabar".

\section{METODE PENELITIAN}

\section{Metode Pemulusan Eksponensial (Exponential Smoothing)}

Metode Exponential Smoothing merupakan prosedur perbaikan terus menerus pada peramalan terhadap objek pengamatan terbaru [5]. Metode peramalan ini menitikberatkan pada penurunan prioritas secara eksponensial pada objek pengamatan yang lebih tua. Metode Single Exponential Smoothing adalah suatu prosedur yang mengulang perhitungan secara terus menerus yang menggunakan data terbaru. Setiap data diberi bobot, dimana bobot yang digunakan disimbolkan dengan $\alpha$. Symbol $\alpha$ bisa ditentukan secara bebas yang mengurangi forecast error. Nilai konstanta pemulusan $\alpha$ dapat dipilih antara nilai 0 dan karena berlaku: $0<\alpha<1$ [4]. Persamaan penulisan eksponensial adalah sebagai berikut:

$$
F_{t}=F_{t-1}+\propto\left(A_{t-1}-F_{t-1}\right)
$$

Keterangan:

$\mathrm{F}=$ nilai ramalan untuk periode waktu ke-t

$F_{t-1}=$ nilai ramalan untuk waktu yang lalu,, t-1

$A_{t-1}=$ nilai actual untuk satu periode waktu yang lalu, $\mathrm{t}_{1}$

$\alpha=$ konstanta penghalusan $(0<\alpha<1)$

\section{Metode Regresi Linier}

Ada metode ini ramalan disusun atas dasar pola hubungan data yang relevan di masa lalu. Ada tiga kondisi untuk dapat mempergunakan Metode Regresi Linier ini, yaitu sebagai berikut:

a. Adanya informasi tentang keadaan yang lalu.

b. Informasi tersebut dapat dikuantifikasikan dalam bentuk kata. 
c. Dapat dianggap atau diasumsikan bahwa pola hubungan yang ada dan data yang telah lalu akan berkelanjutan di masa yang akan datang.

Pola yang ditunjukkan dengan Analisa Regresi Linier yang sederhana mengasumsikan bahwa hubungan diantara 2 variabel dapat dinyatakan dengan suatu garis lurus. Notasi Regresi Linier yang merupakan pola garis lurus itu.[10].

$$
Y=a+b X
$$

Dimana $\mathrm{Y}$ adalah variabel yang diramalkan, $\mathrm{x}$ adalah variabel waktu, serta $a$ dan $b$ adalah parameter atau koefisien regresi Linier, untuk mendapatkan nilai a dan b maka bisa didapatkan dari rumus berikut:

$$
\begin{aligned}
& a=\frac{\sum y}{n}-b \frac{\sum y}{n} \\
& b=\frac{\left(n \cdot \sum x y\right)-\left(\sum x \cdot \sum y\right)}{\left(n \cdot \sum x^{2}\right)-\left(\sum x\right)^{2}}
\end{aligned}
$$

Rumus MAD (Mean Absolute Error), MAPE (Mean Absolute Presetage Error) dan MSD (Mean Squared Deviation) yang terdapat adalah

$$
\begin{aligned}
& \text { MAPE }=\sum \frac{\left[\frac{A-F}{A}\right\rfloor \times 100 \%}{n} \\
& M S D=\sum \frac{(A-F)^{2}}{n} \\
& M A D=\sum \frac{A-F}{n}
\end{aligned}
$$

Dimana

$\mathrm{Y}$ : nilai yang diramalkan

A : konstanta (Intercept)

$\mathrm{b}$ : koefisien regresi (Slope)

$\mathrm{X}$ : variabel yang mempengaruhi (waktu: tahun, bulan, hari)

$\mathrm{N}$ : jumlah data

\section{Jadwal Induk Produksi (Master Production Schedule/MPS)}

MPS merupakan gambaran atasperiode perencanaan dari suatu permintaan, termasuk peramalan, backlog, rencana suplai/penawaran, persediaan akhir, serta kuantitas yang dijanjikan tersedia (available to promise). Jadwal induk produksi disusun berdasarkan perencanaan produksi agregat dan merupakan kunci penghubung dalam rantai perencanaan dan pengendalian produksi [7]. MPS pada dasarnya merupakan suatu pernyataan tentang produk akhir (termasuk parts pengganti dan suku cadang) dari suatu perusahaan industri manufaktur yang merencanakan memproduksi output berkaitan dengan kuantitas dan periode waktu [4].

\section{Metode Pengambilan Data}

Objek penelitian ini adalah pada tinta yang digunakan pada produksi koran PT. XYZ. Tinta yang digunakan adalah tinta berwarna (fullcolour) yaitu tinta merah (web magenta), tinta biru (web cyan), tinta kuning (web yellow) dan tinta hitam (web black). Penelitian dilakukan pada perusahaan percetakan Surat Kabar PT. XYZ, Banjarbaru, Kalimantan Selatan.

Adapun alat penunjang untuk mendapatkan penelitian yaitu: a. Data pemakaian tinta fullcolour Pada Bulan Agustus sampai Oktober 2015

b. Kamera Handphone Asus Zenfone 5

c. Microsoft Excel 2010

d. Microsoft Office Visio 2007

e. Software Minitab17

\section{Tahapan Penelitian}

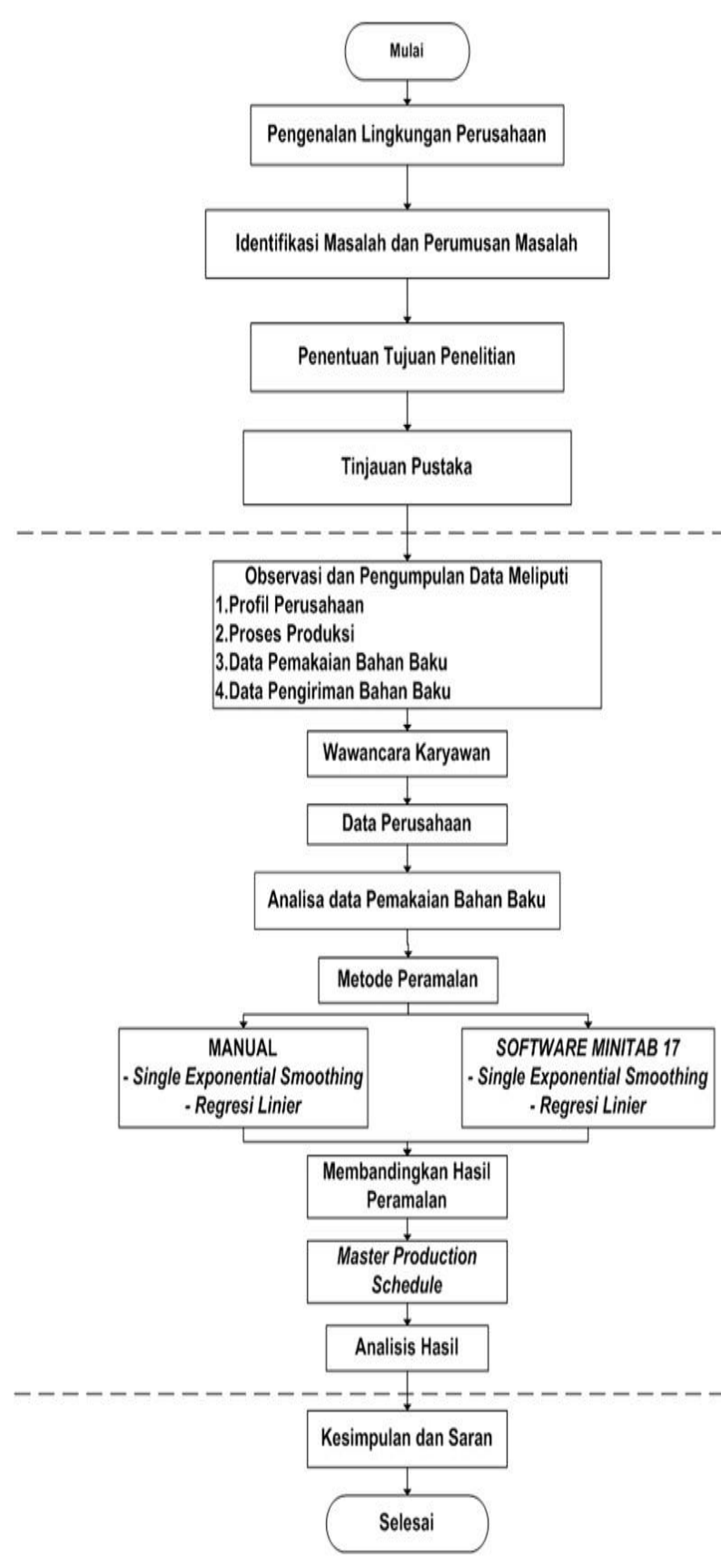

Gambar 1. Tahapan Penelitian 


\section{HASIL DAN PEMBAHASAN}

Dari hasil pengamatan yang telah dilakukan terhadap pemakaian 4 (empat) jenis tinta yaitu Cyan (C), Magenta (M), Yellow (Y) dan Black (B), maka diperoleh data pemakaian tinta dari Bulan September sampai November 2015.

Tabel 1. Data Pemakaian Tinta

\begin{tabular}{|c|c|c|c|c|c|}
\hline \multirow{2}{*}{ Periode } & \multirow{4}{*}{ Minggu } & \multicolumn{4}{|c|}{ Jumlah Pemakaian (kg) } \\
\cline { 3 - 6 } & & $\boldsymbol{C}$ & $\boldsymbol{M}$ & $\boldsymbol{Y}$ & $\boldsymbol{B}$ \\
\hline \multirow{7}{*}{$\mathbf{5 0 1 5}$} & Minggu 1 & 5 & 4 & 8 & 21 \\
\cline { 2 - 6 } & Minggu 2 & 5 & 4 & 8 & 21 \\
\cline { 2 - 6 } & Minggu 3 & 5,5 & 4,5 & 5,5 & 21 \\
\cline { 2 - 6 } & Minggu 4 & 4,5 & 7 & 3,5 & 21 \\
\cline { 2 - 6 } & Minggu 5 & 3,5 & 3,5 & 5 & 21 \\
\cline { 2 - 6 } & Minggu 6 & 3,5 & 3,5 & 5,5 & 21 \\
\cline { 2 - 6 } & Minggu 7 & 3,5 & 3,5 & 5,5 & 21 \\
\cline { 2 - 6 } & Minggu 8 & 5 & 5 & 8 & 30 \\
\cline { 2 - 6 } & Minggu 9 & 7,5 & 3,5 & 4,5 & 21 \\
\cline { 2 - 6 } & Minggu 10 & 3,5 & 3,5 & 5 & 28 \\
\cline { 2 - 6 } & Minggu 11 & 3,5 & 3,5 & 5 & 19 \\
\cline { 2 - 6 } & Minggu 12 & 4,5 & 4,5 & 8 & 26 \\
\hline \multirow{7}{*}{ Jumlah } & $\mathbf{1 2}$ & $\mathbf{5 4 , 5}$ & $\mathbf{5 0}$ & $\mathbf{7 1 , 5}$ & $\mathbf{2 7 1}$ \\
\hline
\end{tabular}

Data pemakaian tinta mengasumsikan pemakaian 4 warna tinta sebagai data histori. Dari data pemakaian tinta tersebut, maka dapat dilakukan suatu peramalan untuk pemakaian tinta pada percetakan surat kabar PT. XYZ pada periode selanjutnya.

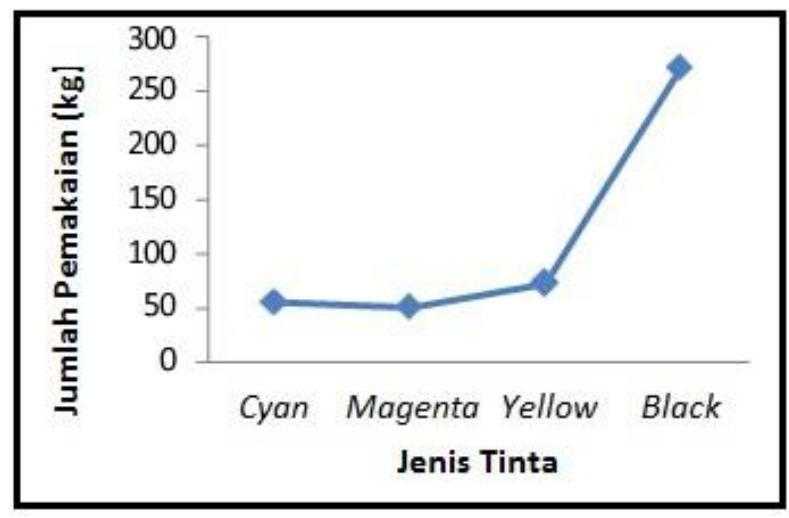

Gambar 2. Grafik Pemakaian Tinta dari Bulan September sampai November 2015

Rata-rata pemakaian Tinta Web Cyan, Web Magenta dan Web Yellow adalah $50 \mathrm{Kg}$. Hal ini dipengaruhi 24 halaman surat kabar yang diproduksi ada 6 halaman warna dan 18 halaman yang mencetak khusus warna hitam (Black) sudah jelas terlihat bahwa pemakaian hitam lebih banyak dari pada 3 macam tinta lainnya.
Jadwal Induk Produksi (Master Production Schedule)

Pada Metode Agregat adalah metode yang saling berhubungan satu dengan yang lain (family) disebut Agregat merupakan gambaran atas periode perencanaan da suatu permintaan termasuk ramalan.

Tabel 2. Perbandingan Hasil Peramalan Dan Ukuran Akurasi Metode Single Exponential Smoothing

\begin{tabular}{|c|c|c|c|c|}
\hline \multirow{2}{*}{\begin{tabular}{c}
\multirow{2}{*}{$\begin{array}{c}\text { Jenis } \\
\text { Tinta }\end{array}$} \\
\cline { 2 - 5 }
\end{tabular}} & \multicolumn{4}{|c|}{ Single Exponential Smoothing } \\
\cline { 2 - 5 } & MAD & MSD & MAPE & $\begin{array}{c}\text { Periode } \\
\text { Berikut }\end{array}$ \\
\hline Cyan & 0,876 & 1,937 & 19,943 & 4,55 \\
\hline Magenta & 0,809 & 1,695 & 18,541 & 4,5 \\
\hline Yellow & 1,310 & 3,137 & 24,492 & 8 \\
\hline Black & 3,222 & 24,461 & 13,478 & 25,5 \\
\hline \multirow{2}{*}{$\begin{array}{c}\text { Jenis } \\
\text { Tinta }\end{array}$} & MAD & Software Minitab 17 \\
\hline Cyan & 1,037 & 2,242 & 23,341 & 4,4 \\
\hline Magenta & 0,925 & 1,887 & 21,397 & 4,4 \\
\hline Yellow & 1,495 & 3,624 & 26,743 & 7,7 \\
\hline Black & 3,153 & 24,428 & 13,207 & 25,4 \\
\hline
\end{tabular}

Tabel 3. Perbandingan Hasil Peramalan Dan Ukuran Akurasi Metode Regresi Linier

\begin{tabular}{|c|c|c|c|c|}
\hline \multirow{2}{*}{\begin{tabular}{c}
\multirow{2}{*}{$\begin{array}{c}\text { Jenis } \\
\text { Tinta }\end{array}$} \\
\cline { 2 - 5 }
\end{tabular}} & \multicolumn{4}{|c|}{ Regresi Linier } \\
\cline { 2 - 5 } Cyan & 0,844 & 1,284 & 18,614 & 4,235 \\
\hline Magenta & 0,733 & 0,920 & 16,390 & 3,735 \\
\hline Yellow & 1,332 & 2,313 & 23,513 & 5,583 \\
\hline Black & 2,148 & 8,883 & 9,143 & 25,152 \\
\hline \multirow{2}{*}{$\begin{array}{c}\text { Jenis } \\
\text { Tinta }\end{array}$} & MAD & MSD & MAPE & $\begin{array}{c}\text { Periode } \\
\text { Berikut }\end{array}$ \\
\cline { 2 - 5 } & Software Minitab 17 \\
\hline Cyan & 0,844 & 1,284 & 18,614 & 4,235 \\
\hline Magenta & 0,733 & 0,920 & 16,390 & 3,735 \\
\hline Yellow & 1,332 & 2,313 & 23,513 & 5,583 \\
\hline Black & 2,148 & 8,883 & 9,143 & 25,152 \\
\hline
\end{tabular}




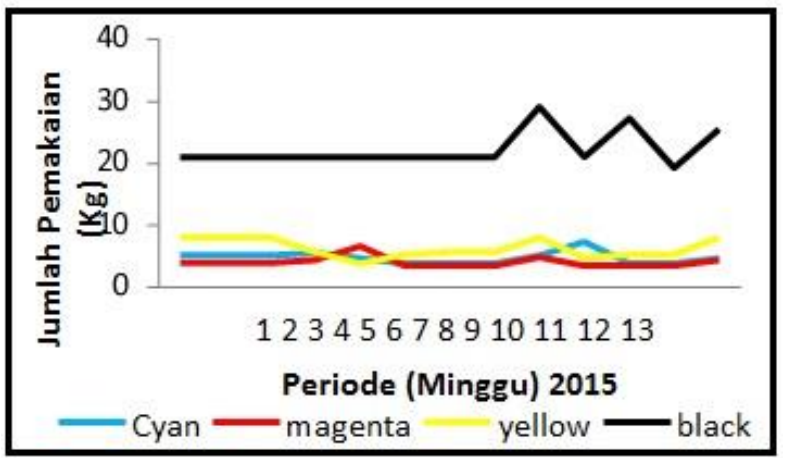

Gambar 3. Grafik Peramalan Dengan Metode Single Exponential Smoothing

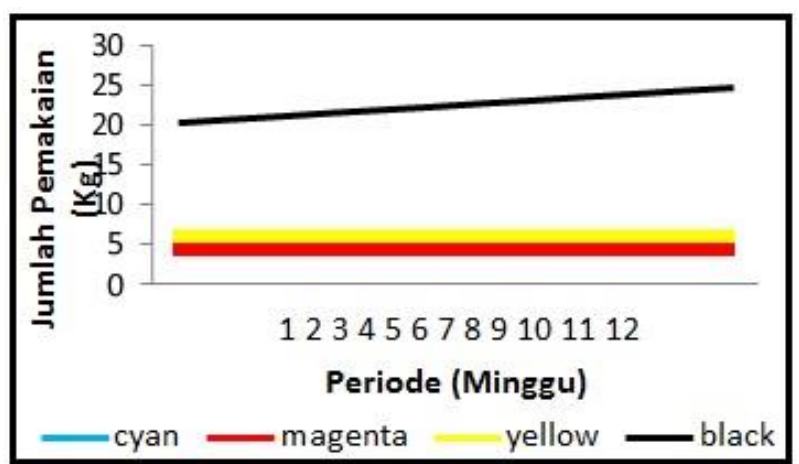

Gambar 4. Grafik Peramalan dengan Metode Regresi Linier

Tabel 4 Hasil Dari Peramalan Pemakaian MasingMasing Tinta Dalam Bentuk

\begin{tabular}{|c|c|c|c|c|c|}
\hline $\begin{array}{c}\text { Periode } \\
\text { (bulan) }\end{array}$ & Cyan & $\begin{array}{c}\text { Magent } \\
\boldsymbol{a}\end{array}$ & $\begin{array}{c}\text { Yello } \\
\boldsymbol{w}\end{array}$ & Black & $\begin{array}{c}\text { Family } \\
\boldsymbol{X}\end{array}$ \\
\hline $\mathbf{1}$ & 350 & 280 & 560 & 1470 & 2660 \\
\hline $\mathbf{2}$ & 350 & 280 & 560 & 1470 & 2660 \\
\hline $\mathbf{3}$ & 385 & 315 & 385 & 1470 & 2555 \\
\hline $\mathbf{4}$ & 315 & 490 & 245 & 1470 & 2520 \\
\hline $\mathbf{5}$ & 245 & 245 & 350 & 1470 & 2310 \\
\hline $\mathbf{6}$ & 245 & 245 & 385 & 1470 & 2345 \\
\hline $\mathbf{7}$ & 245 & 245 & 385 & 1470 & 2345 \\
\hline $\mathbf{8}$ & 350 & 350 & 560 & 2100 & 3360 \\
\hline $\mathbf{9}$ & 525 & 245 & 315 & 1470 & 2555 \\
\hline $\mathbf{1 0}$ & 245 & 245 & 350 & 1960 & 2800 \\
\hline $\mathbf{1 1}$ & 245 & 245 & 350 & 1330 & 2170 \\
\hline $\mathbf{1 2}$ & 315 & 315 & 560 & 1820 & 3010 \\
\hline $\mathbf{1 3}$ & 350 & 350 & 490 & 1680 & 2870 \\
\hline Total & $\mathbf{4 1 6 5}$ & $\mathbf{3 8 5 0}$ & $\mathbf{5 4 9 5}$ & $\mathbf{2 0 6 5 0}$ & $\mathbf{3 4 1 6 0}$ \\
\hline & & & & & \\
\hline
\end{tabular}

Untuk harga pemakaian Tinta Web Cyan selanjutnya $350 \times 1000$ $350.000: 70.000$ $=$ Rp. $350.000,00$ $=5 \mathrm{Kg}$
Untuk harga pemakaian Tinta Web Magenta selanjutnya:

$$
\begin{array}{ll}
350 \times 1000 & =\text { Rp. } 350.000,00 \\
350.000: 70.000 & =5 \mathrm{Kg}
\end{array}
$$

Untuk harga pemakaian Tinta Web Yellow selanjutnya

$$
\begin{array}{ll}
490 \times 1000 & =\text { Rp. } 490.000,00 \\
490.000: 70.000 & =7 \mathrm{Kg}
\end{array}
$$

Untuk harga pemakaian Tinta Web Black selanjutnya

$$
\begin{array}{ll}
1680 \times 1000 & =\text { Rp. } 1.680 .000,00 \\
1.680 .000: 70.000 & =24 \mathrm{Kg}
\end{array}
$$

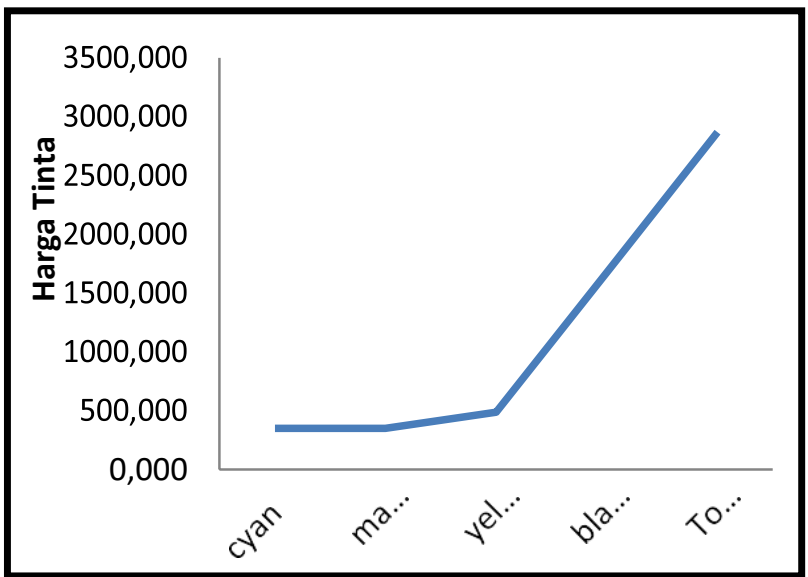

Gambar 5. Grafik Harga Pemakaian Tinta

Jadi dari hasil peramalan untuk yang akan datang tidak jauh lebih dari pemakaian sebelumnya seperti sebagai berikut:

- Tinta Web Cyan minggu ke 12 sebesar 4,282 kg tidak jauh beda minggu ke 13 sebesar 4,235 kg.

- Tinta Web Magenta minggu ke 12 sebesar 3,801 kg tidak jauh beda minggu ke 13 sebesar $3,735 \mathrm{~kg}$.

- Tinta Web Yellow minggu ke 12 sebesar 5,641 kg tidak jauh beda minggu ke 13 sebesar $5,583 \mathrm{~kg}$.

- Tinta Web Black minggu ke 12 sebesar 24,756 kg tidak jauh beda minggu ke 13 sebesar $25,152 \mathrm{~kg}$.

\section{KESIMPULAN}

Berdasarkan dari kedua hasil perhitungan peramalan yang telah dilakukan menghasilkan nilai melalui Software Minitab 17 khususnya untuk Metode Regresi Linier diperoleh nilai kesalahan yang lebih kecil, Sedangkan untuk perencanaan produksi dari Master Production Schedule untuk yang akan datang pada kapasitas dan harga tinta yang akan datang pada Tinta Web Cyan $5 \mathrm{~kg}$ untuk kapasitas tinta dan Rp 350.000 untuk harga tinta, pada Tinta Web Magenta $5 \mathrm{~kg}$ untuk kapasitas tinta dan Rp 350.000 untuk harga tinta, pada Tinta Web Yellow $7 \mathrm{~kg}$ untuk kapasitas tinta dan Rp 490.000 
dan pada Tinta Web Black $24 \mathrm{~kg}$ untuk kapasitas tinta dan Rp 1.680.000 untuk harga tinta.

\section{SARAN}

Dari temuan permasalahan dan hasil penelitian disampaikan saran perbaikan adalah perlu adanya penelitian lebih lanjut proses produksi surat kabar selain tinta.

\section{DAFTAR PUSTAKA}

[1] Arsyad, Lincolin, Peramalan Bisnis, Edisi pertama, BPFE Yogyakarta, 1997.

[2] Djuroto, Totok., Managemen Penerbitan Pers. Bandung:

Rosdakarya,.2000.

[3] Effendy, Onong Uchjana., Ilmu Komunikasi: Teori dan Praktek. Bandung: Remaja Rosdakarya, 2005.
[4] Gaspersz, Vincent, Production Planning and Inventory Control, Gramedia Pustaka Utama, Jakarta, 2004.

[5] Makridakis, Spyros dan Wheelwright, Steven C. Metode dan Aplikasi Peramalan. Binarupa Aksara, Jakarta, 1999.

[6] Mukhyi, M.A... Forecasting. <URL:http://www.mukhyi.staff.g unadarma.ac.id/Downloads/files/9 309/FORECASTING.pdf>[Acces ed 23July 2010], 2008.

[7] Nugroho, Theoderus P., Materi Kuliah Pracetak II, STIKOM, Surabaya, 2009.

[8] Nugroho, Theoderus P., Materi Kuliah Pracetak I, STIKOM, Surabaya, 2010.

[9] Render dan Hizer, Prinsip-Prinsip Manajemen Operasi, Salemba Empat, Jakarta, 2005.

[10] Subagyo, Pangestu, " Forecasting Konsep dan Aplikasi “, BPFE. Jakarta. 2002.

[11] Sumadiria, Haris., Jurnalistik Indonesia. Menulis berita dan Feature. Panduan Praktis Jurnalistik Profesional. Bandung: Rosdakarya, 2006. 